Tersedia online di

\title{
Perbandingan Daya Dukung Tiang Pancang Berdasarkan Pengujian Cone \\ Penetration Test (CPT) Dan Standard Penetration Test (SPT) Pada Tanah
}

\section{Berpasir}

\author{
I W. A. Basoka ${ }^{1}$ \\ ${ }^{\text {I}}$ Fakultas Teknik dan Perencanaan, Universitas Warmadewa, Denpasar. \\ email: basokaariyana@gmail.com
}

\begin{tabular}{|c|c|}
\hline \multicolumn{2}{|c|}{ A R T I C L E I N F O } \\
\hline Artikel History : & \\
\hline Artikel masuk & : 01-04-2020 \\
\hline Artikel revisi & : 03-04-2020 \\
\hline Artikel diterima & : 04-04-2020 \\
\hline
\end{tabular}

Keywords :

Bearing Capacity, Foundation, $C P T, S P T$.

Style IEEE dalam mensitasi artikel ini : [4]

$P$. Jarast and M. Ghayoomi, "Numerical Modeling of Cone Penetration Test in Unsaturated Sand inside a Calibration Chamber," Int. J. Geomech., vol. 18, no. 2, 2018.

\begin{abstract}
A B S TRACT
Design of building structure always related with foundation, field testing is often done to test the bearing capacity of the soil in the form of a cone penetration test (CPT) and a standard penetration test (SPT). From the two field tests that are often done, it is necessary to do research on the amount of bearing capacity obtained through CPT and SPT data. This study uses a bearing capacity analysis of the pile foundation using CPT and SPT data in Pesanggaran, Bali, Indonesia. The analysis was carried out by comparing the bearing capacity of pile foundations using pile foundations with dimensions of $15 \mathrm{~cm}, 20 \mathrm{~cm}, 25 \mathrm{~cm}$ and $30 \mathrm{~cm}$ at a level of 10 meters. The results of the bearing capacity percentage are then compared. From the analysis conducted, the bearing capacity of pile foundations using CPT data has a higher value than the carrying capacity of poles using SPT data with a bearing capacity difference of 10,4-16,3\%.
\end{abstract}

\section{A B S T R A K}

Perancangan suatu struktur erat kaitannya dengan fondasi, pengujian lapangan yang sering dilakukan untuk mengetahui daya dukung fondasi berupa cone penetration test (CPT) dan standard penetration test (SPT). Dari dua pengujian lapangan yang sering dilakukan, maka perlu dilakukan dilakukan penelitian mengenai seberapa besar perbedaan hasil daya dukung yang diperoleh melalui data CPT dan SPT. Penelitian ini melakukan perbandingan analisis daya dukung fondasi tiang dengan menggunakan data CPT dan SPT di Pesanggaran, Bali, Indonesia. Analisis dilakukan dengan membandingkan daya dukung fondasi tiang menggunakan fondasi tiang berdimensi $15 \mathrm{~cm}, 20 \mathrm{~cm}, 25$ $\mathrm{cm}$, dan $30 \mathrm{~cm}$ pada kedalaman 10 meter. Hasil persentase daya dukung yang diperoleh kemudian dibandingkan. Dari analisis yang dilakukan, diperoleh daya dukung fondasi tiang menggunakan data CPT memiliki nilai lebih tinggi daripada daya dukung tiang menggunakan data SPT dengan perbedaan daya dukung 10,4-16,3\%.

Perbandingan Daya Dukung Tiang Pancang Berdasarkan Pengujian Cone Penetration Test (CPT) Dan Standard Penetration Test (SPT) Pada Tanah Berpasir. 


\section{Pendahuluan}

Perancangan suatu struktur sangat erat kaitannya dengan fondasi, daya dukung fondasi harus dirancang dengan baik sehingga menjamin bangunan terhindar dari masalah differensial settlement yang dapat mengancam nyawa penghuninya [1][2]. Pengujian lapangan yang sering dilakukan untuk mengetahui daya dukung tanah berupa Cone Penetration Test (CPT) dan Standard Penetration Test (SPT). CPT dan SPT memiliki akurasi, pengoperasian, dan keandalan yang lebih baik dibandingkan dengan tes lapangan lainnya sehingga sering menjadi pilihan pengujian lapangan [3]. CPT adalah pengujian geoteknik yang populer, metode investigasi lapangan digunakan untuk mengevaluasi sifat fisik dan mekanik tanah. Ada banyak mekanika berbasis korelasi empiris yang menghubungkan resistansi kerucut/konus (qc), dan tahanan gesek (fs) [4]. Uji penetrasi kerucut (CPT) adalah alat yang terbukti untuk pengujian tanah in situ. Metode pengujian dapat memberikan data untuk evaluasi parameter desain geoteknik penting, penggambaran profil tanah yang berbeda di dalam tanah, perhitungan kapasitas dukung tiang, dan penilaian potensi likuifaksi [5][6]. Vanapalli dan Mohamed (2013) juga melakukan beberapa pengujian CPT dalam tangki yang dirancang khusus dan menunjukkan pengaruh yang berarti dari pengisapan pada resistensi kerucut (qc) dan daya dukung pasir. Uji Penetrasi Standar atau Standard Penetration Test (SPT) dapat pula digunakan dalam perhitungan daya dukung pondasi meski hanya sebagai perkiraan awal (preliminary value) dan harus dibandingkan dengan hasil perhitungan empiris yang menggunakan hasil pengujian di laboratorium [8][9].

Setelah kejadian di Petobo, Palu 2018, menjadikan penyelidikan tanah yang mendalam sangat penting untuk dilakukan. Insiden itu menyebabkan banyak nyawa dan kerusakan parah pada infrastruktur [10]. Dalam penelitian ini dilakukan penyelidikan mendalam mengenai daya dukung fondasi yang berlokasi di daerah Pesanggaran, Denpasar, Bali. Pemilihan lokasi ini mengingat di sekitar Pesanggaran terdapat fasilitas yang krusial seperti Depo Pertamina, PLN, dan Pelabuhan. Tiang pancang atau kelompok tiang sebagai fondasi berperforma baik di berbagai jenis tanah dengan mentransmisikan beban secara aman dari superstruktur dan mengurangi masalah yang terkait dengan penyelesaian [11]. Kelompok tiang banyak digunakan sebagai fondasi ketika beban aksial besar seperti yang berasal dari bangunan bertingkat tinggi, dermaga jembatan, pembangkit listrik, atau struktur berat lainnya harus dipindahkan ke tanah [12].

Perbandingan Daya Dukung Tiang Pancang Berdasarkan Pengujian Cone Penetration Test (CPT) Dan Standard Penetration 


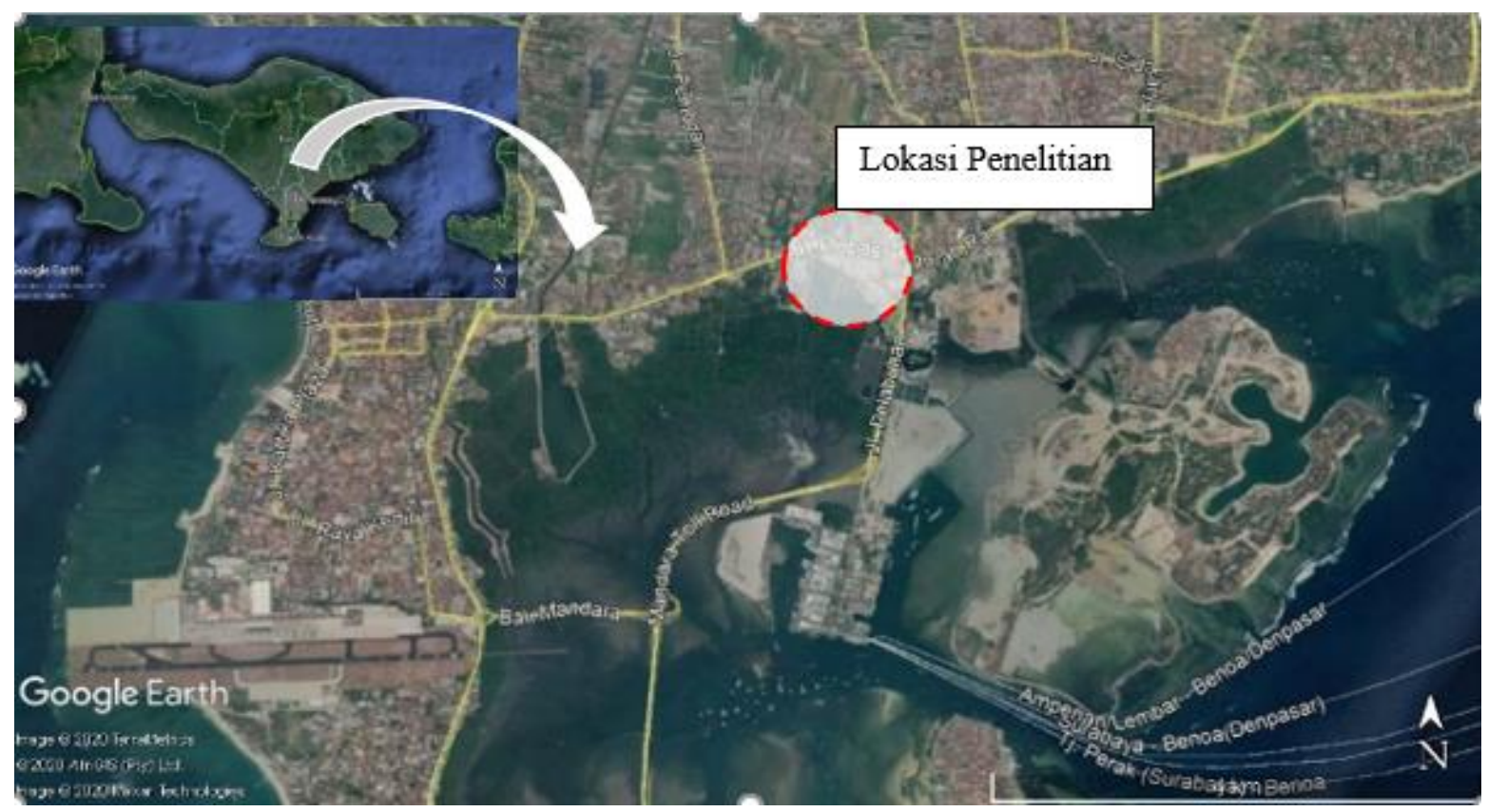

Sumber: Peta Lokasi Penelitian.

Gambar 1. Lokasi Penelitian.

Tanah di wilayah berpasir biasanya dalam kondisi tidak jenuh, dan karenanya perilaku interaksi mekanis tanah dan struktur tanahnya secara signifikan dipengaruhi oleh matriks suction [13]. Dari dua pengujian lapangan yang sering dilakukan ini (CPT dan SPT) maka perlu dilakukan dilakukan penelitian mengenai seberapa besar perbedaan hasil daya dukung yang diperoleh.

\section{Tinjauan Pustaka}

\subsection{Cone Penetration Test (CPT).}

Cone Penetration Test (CPT) atau sering disebut sondir, merupakan salah satu pengujian lapangan yang digunakan untuk mengetahui daya dukung tanah di suatu lokasi. Selain cepat, biaya pengujian CPT relatif lebih murah dibandingkan pengujian SPT, sehingga pengujian CPT sering dipergunakan di lapangan. Pendekatan menggunakan data CPT untuk memperkirakan sudut gesekan dikembangkan dari pengujian pada pasir bersih, dan pendekatan ini biasanya digunakan untuk memperkirakan sudut gesekan tanah granular [14][15]. Beberapa pengujian berupa analisis numerik dan eksperimental kapasitas dukung ujung tiang di tanah berlapis juga dapat dilakukan menggunakan pengujian CPT [16][17][18].

Tahanan ujung yang termobilisasi pada tiang pancang harus setara dengan tahanan ujung saat uji penetrasi. Tetapi, pengaruh skala dan perbedaan kecepatan pembebanan

Perbandingan Daya Dukung Tiang Pancang Berdasarkan Pengujian Cone Penetration Test (CPT) Dan Standard Penetration Test (SPT) Pada Tanah Berpasir. 
menyebabkan perbedaan signifikan pada nilai tahanan ujung tiang (Hardiyatmo, 2010). Kapasitas dukung ultimit neto $\left(Q_{u}\right)$, dihitung dengan Persamaan 1.

$$
Q_{u}=Q_{b}+Q_{s}-W_{p}=A_{b} f_{b}+A_{s} f_{s}-W_{p}
$$

Dengan :

$A_{b} \quad=$ luas ujung bawah tiang.

$A_{b} \quad=$ luas ujung bawah tiang.

$A_{s} \quad=$ luas selimut tiang.

$f_{s} \quad=$ tahanan ujung satuan tiang.

$f_{b} \quad=$ tahanan gesek satuan tiang.

$W_{p}=$ tahanan gesek satuan tiang.

Perhitungan daya dukung tiang pada tanah berpasir menggunakan persamaan Mayerhof (1976; 1983) dalam Hardiyatmo [19].

1. Tahanan Ujung.

Tahanan ujung untuk tiang pancang pada tanah berpasir dihitung dengan Persamaan 2.

$$
f_{b}=\omega_{1} \omega_{1} q_{c a}
$$

Dengan :

$f_{b} \quad=$ Tahanan ujung satuan, untuk tiang bor diambil $70 \%$ atau 50\%-nya.

$q_{c a}=$ qc rata-rata $\left(\mathrm{kN} / \mathrm{m}^{2}\right)$ pada zona $1 \mathrm{~d}$ di bawah ujung tiang dan $4 \mathrm{~d}$ di atasnya.

$\omega_{1}=\{(\mathrm{d}+0,5) / 2 \mathrm{~d}\} \mathrm{n} ;$ koefisien modifikasi pengaruh skala, jika $\mathrm{d}>0,5 \mathrm{~m}$. Jika $\mathrm{d}<0,5$ $\mathrm{m}, \omega_{1}=1$.

$\omega_{2}=\mathrm{L} / 10 \mathrm{~d}=$ koefisien modifikasi untuk penetrasi tiang dalam lapisan pasir padat saat $\mathrm{L}<10 \mathrm{~d}$, jika L $>10 \mathrm{~d}, \omega_{2}=1$.

$d \quad=$ Diameter tiang $(\mathrm{m})$.

$L \quad=$ Kedalaman penetrasi tiang di dalam lapisan pasir padat $(\mathrm{m})$.

$n \quad=$ Nilai eksponensial.

$=1$ untuk pasir longgar $(\mathrm{qc}<5 \mathrm{MPa})$.

$=2$ untuk pasir kepadatan sedang $(5 \mathrm{MPa}<\mathrm{qc}<12 \mathrm{MPa})$.

$=3$ untuk pasir padat $(\mathrm{qc}>12 \mathrm{MPa})$. 
2. Tahanan Gesek.

Untuk tiang pancang, tahanan gesek satuan diambil salah satu dari Persmaan 3. atau

Persamaan 4.

$$
f_{s}=K_{f} q_{f}
$$

Dengan $\mathrm{Kf}=1$.

atau, bila tidak dilakukan pengukuran tahanan gesek sisi konus :

$$
f_{s}=K_{c} q_{c}
$$

Dengan $\mathrm{Kc}=0,005$.

Dengan :

is $\quad=$ tahanan gesek satuan $\left(\mathrm{kg} / \mathrm{cm}^{2}\right)$.

$\mathrm{Kt}=$ koefisien modifikasi tahanan gesek sisi konus.

Kc $=$ koefisien modifikasi tahanan konus.

\subsection{Standard Penetration Test (SPT).}

Uji penetrasi standar dilakukan karena sulitnya memperoleh contoh tanah tak terganggu pada tanah granuler. Pada pengujian ini, sifat-sifat tanah pasir ditentukan dari pengukuran kerapatan relative secara langsung di lapangan. Pengujian untuk mengetahui nilai kerapatan relatif yang sering digunakan adalah uji penetrasi standar atau disebut uji SPT (Standar Penetration Test). Prosedur uji SPT tercantum dalam ASTM D 1586 [20]. Selain itu pengujian SPT merupakan cara yang disukai untuk survei geoteknis untuk menentukan litologi bawah permukaan dan untuk mendapatkan daya dukung permukaan bawah permukaan. Pengeboran dan SPT memiliki data yang baik karena tes langsung ke tanah untuk mendapatkan data yang sebenarnya [21].

Dalam investigasi besar, data SPT dapat dikalibrasi terhadap data spesifik lapangan dari tes triaksial dan tes lainnya. Tetapi untuk investigasi kecil, korelasi empiris mungkin menjadi satu-satunya cara menggunakan data SPT untuk menilai kekuatan [22]. Selama bertahun-tahun, penggunaan luas SPT telah menyebabkan banyak korelasi empiris yang diterbitkan terkait nilai resistansi penetrasi-tanah $\mathrm{N}$ ke berbagai sifat rekayasa tanah [23]. Kapasitas ultimit tiang dapat dihitung secara empiris dari nilai $\mathrm{N}$ hasil uji SPT melalui persamaan Meyerhof (1976).

Perbandingan Daya Dukung Tiang Pancang Berdasarkan Pengujian Cone Penetration Test (CPT) Dan Standard Penetration Test (SPT) Pada Tanah Berpasir. 
1. Tahanan Ujung.

Tahanan ujung tiang dapat dihitung menggunakan Persamaan 5.

$$
Q_{b}=A_{b}(38 \bar{N})\left(L_{b} / d\right) \leq 380 \bar{N}(\mathrm{kN})
$$

Dengan:

$\bar{N} \quad=$ Nilai $\mathrm{N}$ rata-rata yang dihitung dari 8d diatas dasar tiang sampai 4d di bawah dasar tiang.

Untuk tahanan ujung tiang dengan memperhatikan faktor kedalaman berdasarkan

Persamaan 6.

$$
f_{b}=0,4 N_{60}{ }^{\prime}(L / d) \sigma_{r} \leq 4 N_{60}{ }^{\prime} \sigma_{r}\left(\mathrm{kN} / \mathrm{m}^{2}\right)
$$

2. Tahanan Gesek.

Perhitungan tahanan gesek satuan untuk tiang pancang menurut Mayerhof (1976) seperti pada Persamaan 7.

$$
f_{S}=1 / 50 \sigma_{r} N_{60} \quad\left(\mathrm{kN} / \mathrm{m}^{2}\right)
$$

Dengan :

$f_{b} \quad=$ tahanan ujung satuan $\left(\mathrm{kN} / \mathrm{m}^{2}\right)$.

$f_{s}=$ tahanan gesek satuan $\left(\mathrm{kN} / \mathrm{m}^{2}\right)$.

$\sigma_{r} \quad=$ tegangan referensi $=100 \mathrm{kN} / \mathrm{m}^{2}$.

$N_{60}=\mathrm{N}-\mathrm{SPT}$ yang dikoreksi terhadap pengaruh prosedur lapangan saja.

$N_{60}{ }^{\prime}=\mathrm{N}-\mathrm{SPT}$ yang dikoreksi terhadap pengaruh prosedur lapangan dan tekanan overburden.

$L \quad=$ kedalaman penetrasi tiang $(\mathrm{m})$.

$d \quad=$ diameter tiang $(\mathrm{m})$.

\section{Metode Penelitian}

Penelitian ini berlokasi di daerah Pesanggaran, Denpasar, Bali. Pengambilan data primer berupa pengujian 2 titik CPT dan 2 titik SPT pada lokasi yang berdekatan. Pengambilan data CPT dihentikan hinnga nilai konus menunjukkan nilai $250 \mathrm{~kg} / \mathrm{cm}^{2}$, kemudian pengujian SPT dihentikan hingga kedalaman 30 meter. Kemudian data primer tersebut dianalisis menggunakan metode Mayerhof yang dijelaskan pada bab sebelumnya dan dibandingkan perbedaan hasil kedua metode tersebut dalam bentuk grafik.

Perbandingan Daya Dukung Tiang Pancang Berdasarkan Pengujian Cone Penetration Test (CPT) Dan Standard Penetration Test (SPT) Pada Tanah Berpasir. 


\section{Hasil dan Pembahasan}

Berdasarkan pengujian lapangan yang telah dilakukan didapat beberapa hal yang akan dibahas pada Bab berikut.

\subsection{Hasil Pengujian CPT dan SPT.}

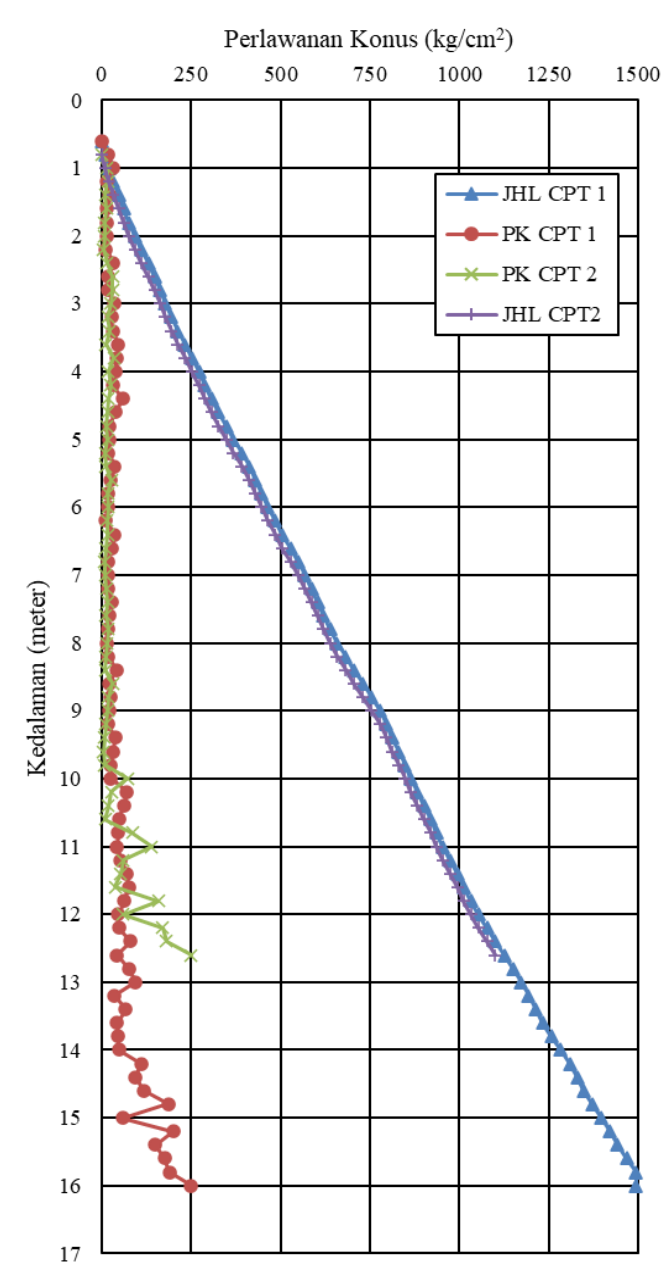

(a)

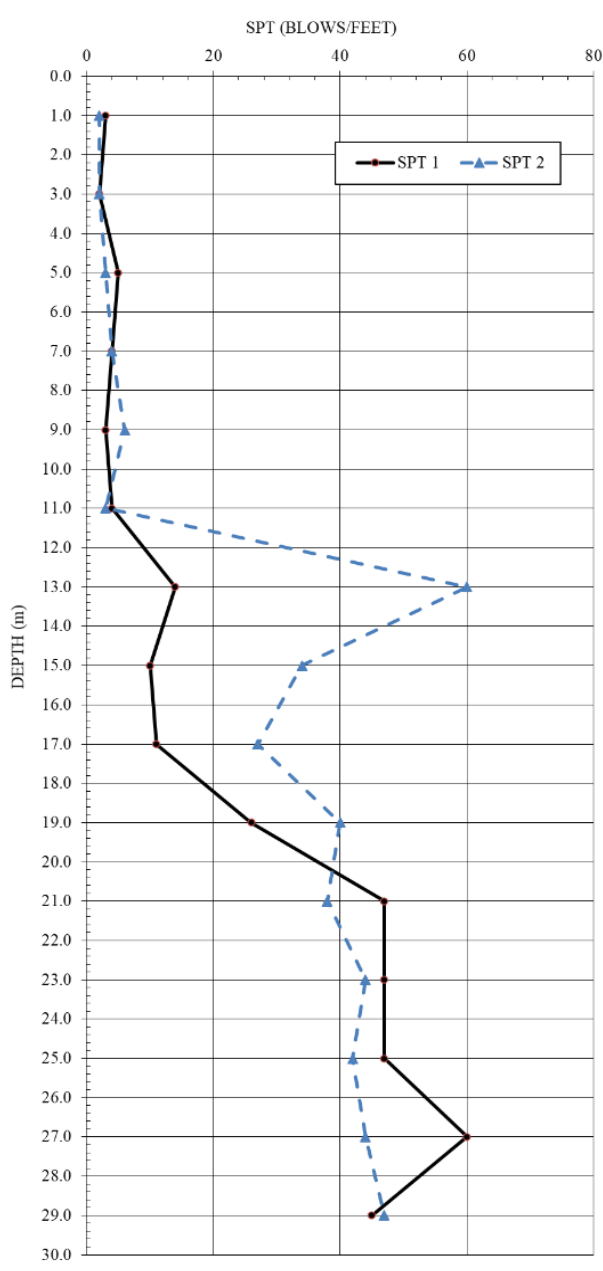

(b)

Sumber: Uji CPT dan SPT Lapangan.

Gambar 2. Hasil Pengujian SPT (a) Uji CPT (b) Uji SPT.

\subsection{Deskripsi Tanah.}

Berdasarkan pengujian CPT S-1 yang disajikan pada Gambar 2a. dapat dilihat dari kedalaman 0.00 meter sampai 0.60 meter berupa urugan. Kemudian dari kedalaman 0.60 meter sampai 14.00 meter nilai konusnya berkisar antara $12 \mathrm{~kg} / \mathrm{cm}^{2}$ sampai $95 \mathrm{~kg} / \mathrm{cm}^{2}$. Kemudian nilai konusnya terus naik dan mencapai nilai tertinggi $250 \mathrm{~kg} / \mathrm{cm}^{2}$ pada kedalaman 16.00 meter. Berdasarkan pengujian CPT S-2 yang disajikan pada Gambar 2a. dari kedalaman 0.00 meter sampai 0.80 meter berupa urugan. Kemudian dari kedalaman 0.80 
meter sampai 11.60 meter nilai konusnya berkisar antara $5 \mathrm{~kg} / \mathrm{cm}^{2}$ sampai $140 \mathrm{~kg} / \mathrm{cm}^{2}$. Kemudian nilai konusnya terus naik dan mencapai nilai tertinggi $250 \mathrm{~kg} / \mathrm{cm}^{2}$ pada kedalaman 12.60 meter.

Berdasarkan pengujian Boring SPT BH-1 yang disajikan pada Gambar $2 \mathbf{b}$. diperoleh jenis tanah dari kedalaman 0.00 meter sampai 0.50 meter berupa urugan. Kemudian dari kedalaman 0.50 meter sampai 3.00 meter berupa lempung kelanuan coklat kehitaman bercampur pasir gradasi halus. Kemudian dari kedalaman 3.00 meter sampai 10.00 meter berupa lanau kepasiran abu-abu keputihan bercampur karang lepas. Kemudian dari kedalaman 10.00 meter sampai 30.00 meter berupa karang lepas berpasir abu-abu keputihan. Ditemukan muka air tanah pada kedalaman -0.50 meter dari muka tanah setempat. Berdasarkan pengujian Boring SPT BH-2 yang disajikan pada Gambar 2b. dari kedalaman 0.00 meter sampai 0.50 meter berupa urugan. Kemudian dari kedalaman 0.50 meter sampai 2.00 meter berupa lempung kelanuan coklat kehitaman bercampur pasir gradasi halus. Kemudian dari kedalaman 2.00 meter sampai 12.00 meter berupa lanau kepasiran abu-abu keputihan bercampur karang lepas. Kemudian dari kedalaman 12.00 meter sampai 21.00 meter berupa karang lepas berpasir abu-abu keputihan. Kemudian dari kedalaman 21.00 meter sampai 30.00 meter berupa pasir keputihan bergradasi sedang hingga kasar bercampur karang lepas. Ditemukan muka air tanah pada kedalaman -0.50 meter dari muka tanah setempat.

Berdasarkan pengujian Boring SPT BH-1 diperoleh nilai N SPT dari kedalaman 0.00 meter sampai dengan 19.00 meter nilai N SPT mencapai berkisar antara 2 pukulan/feet sampai dengan 26 pukulan/feet. Kemudian dari kedalaman 19.00 meter sampai dengan 30.00 meter nilai N SPT mencapai berkisar antara 45 pukulan/feet sampai dengan 60 pukulan/feet. Berdasarkan pengujian Boring SPT BH-2 diperoleh nilai N SPT dari kedalaman 0.00 meter sampai dengan 11.00 meter nilai N SPT mencapai berkisar antara 2 pukulan/feet sampai dengan 6 pukulan/feet. Kemudian dari kedalaman 11.00 meter sampai dengan 30.00 meter nilai N SPT mencapai berkisar antara 27 pukulan/feet sampai dengan 60 pukulan/feet.

\subsection{Daya Dukung Fondasi.}

Berdasarkan perhitungan yang dilakukan dapat diperoleh daya dukung fondasi tiang dengan menggunakan data CPT pada Gambar 3, kemudian daya dukung fondasi tiang menggunakan data SPT pada Gambar 4.

Perbandingan Daya Dukung Tiang Pancang Berdasarkan Pengujian Cone Penetration Test (CPT) Dan Standard Penetration Test (SPT) Pada Tanah Berpasir. 


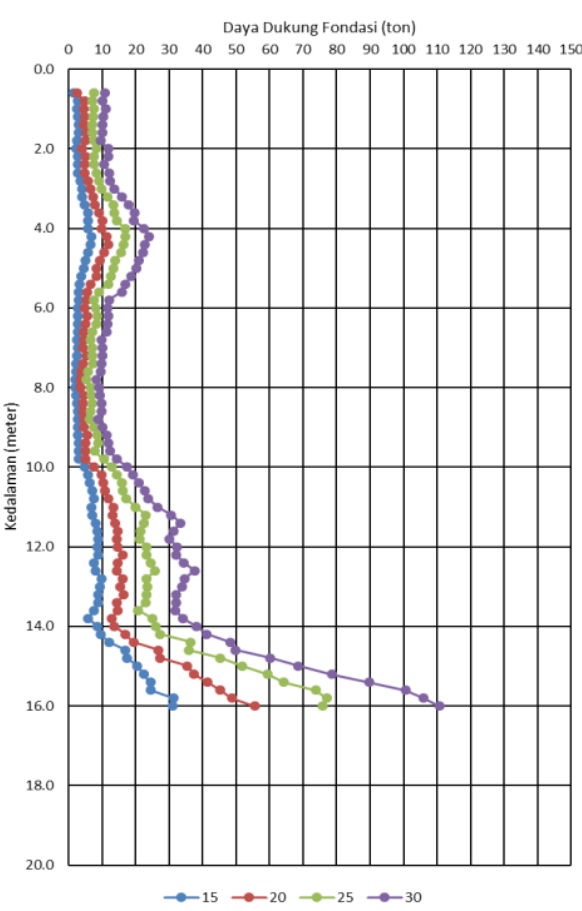

(a)

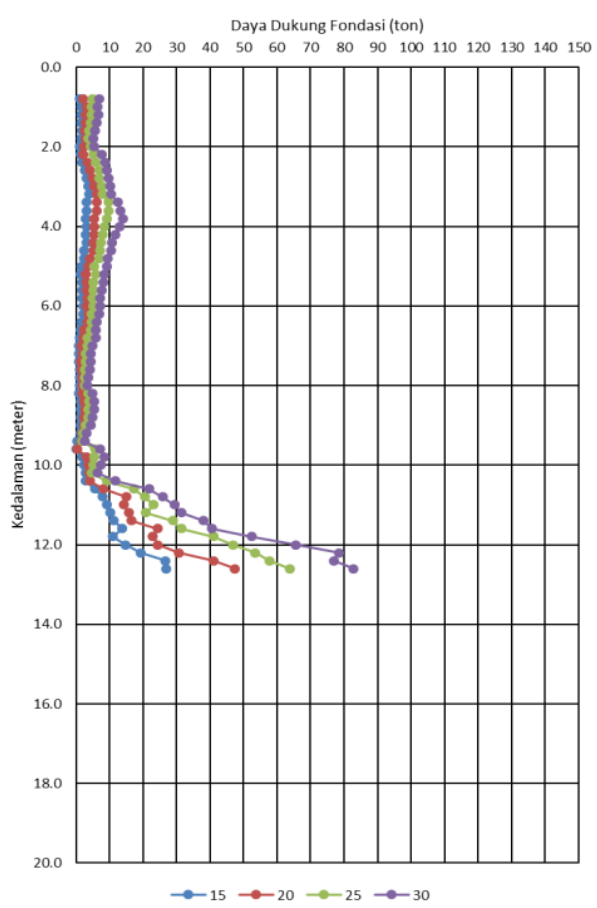

(b)

Sumber: Analisa Daya Dukung Fondasi.

Gambar 3. Hasil Perhitungan Daya Dukung Fondasi (a) CPT S-1, (b) CPT S-2.

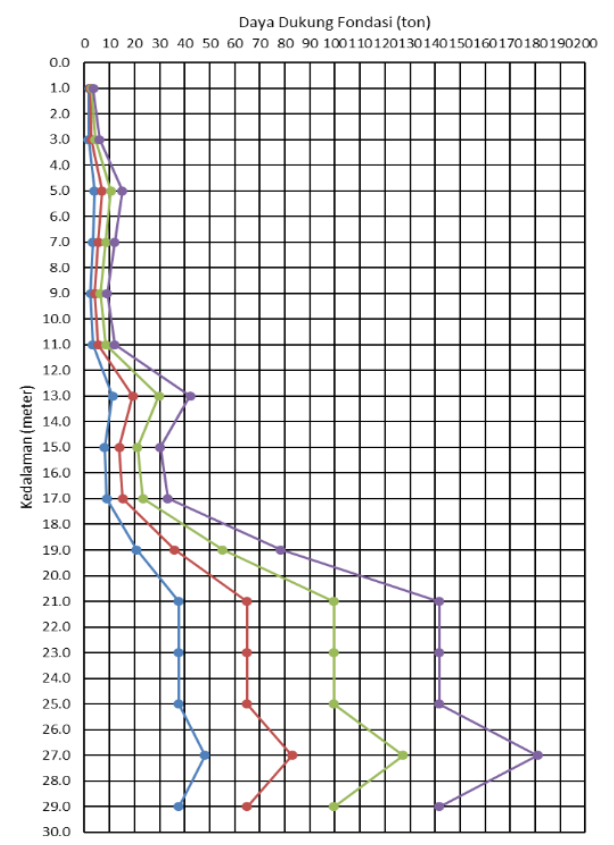

(a)

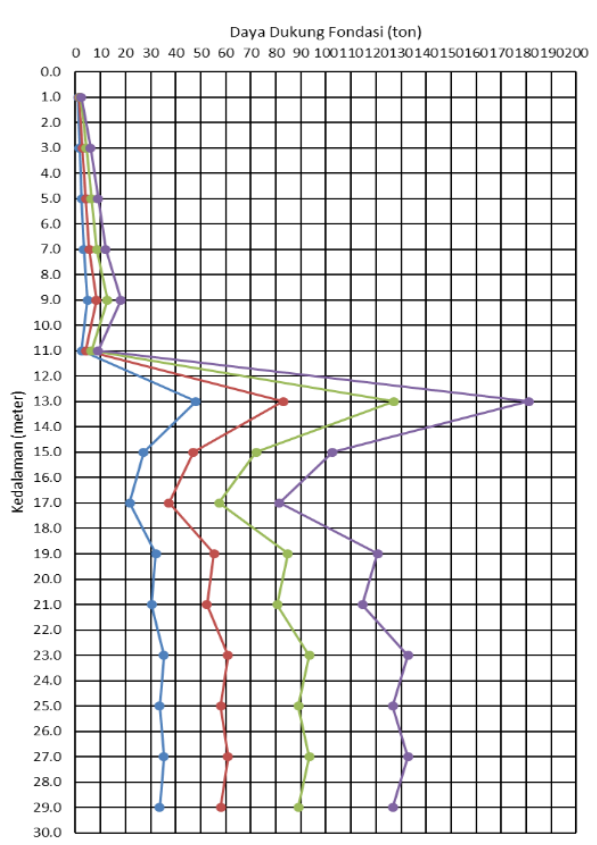

(b)

Sumber: Analisa Daya Dukung Fondasi.

Gambar 4. Hasil Perhitungan Daya Dukung Fondasi (a) SPT BH-1, (b) SPT BH-2.

Perbandingan Daya Dukung Tiang Pancang Berdasarkan Pengujian Cone Penetration Test (CPT) Dan Standard Penetration Test (SPT) Pada Tanah Berpasir. 


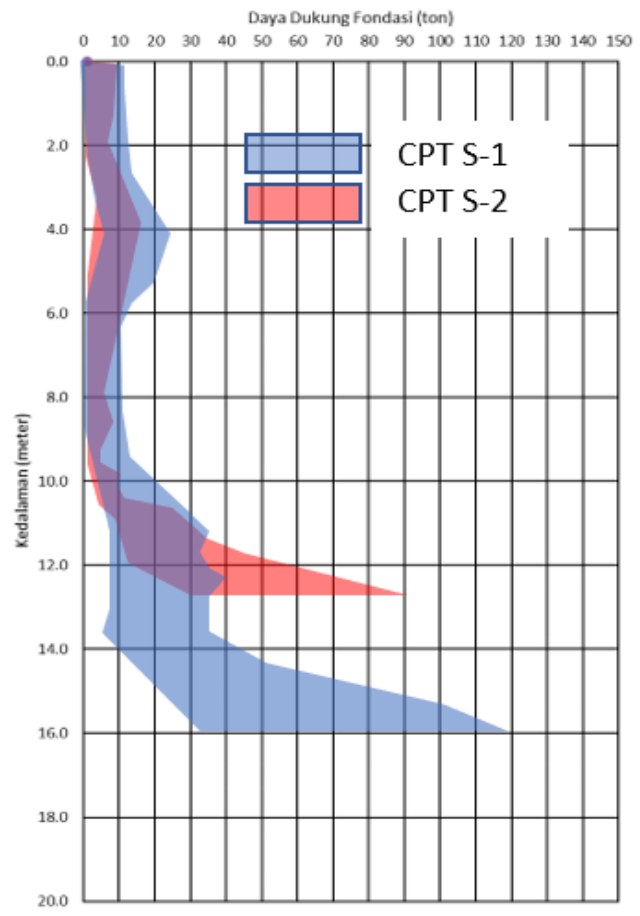

(a)

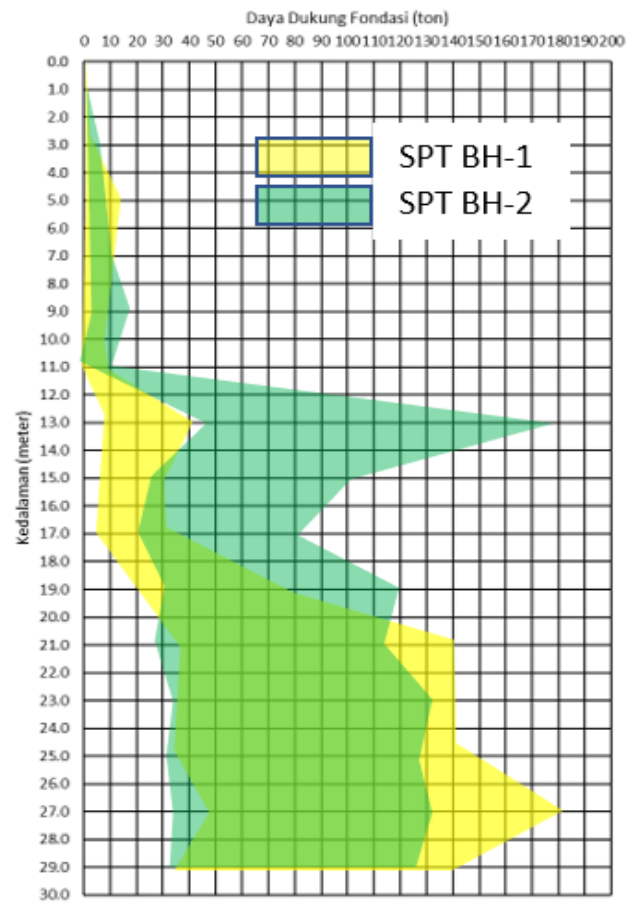

(b)

Sumber: Analisa Daya Dukung Fondasi.

Gambar 5. Perbandingan Daya Dukung Fondasi (a) CPT (b) SPT.

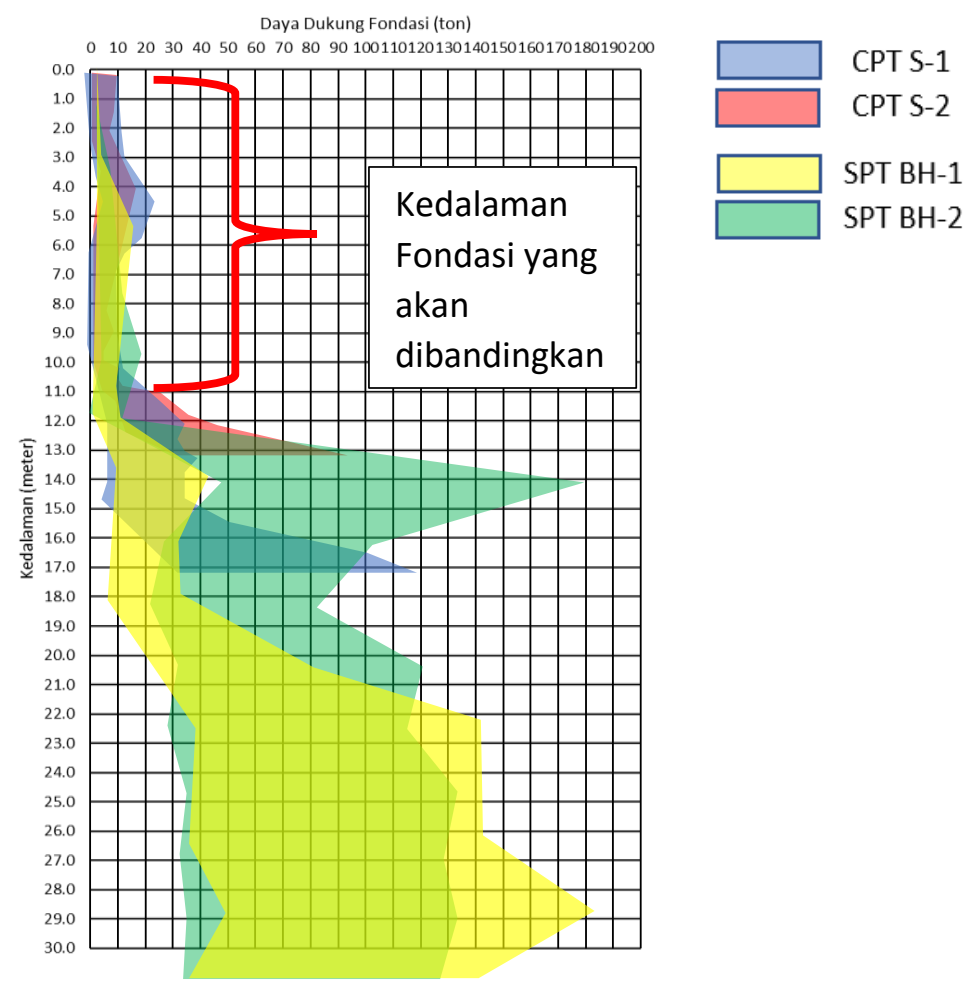

Sumber: Analisa Daya Dukung Fondasi.

Gambar 6. Perbandingan Daya Dukung Fondasi antara CPT dan SPT.

Perbandingan Daya Dukung Tiang Pancang Berdasarkan Pengujian Cone Penetration Test (CPT) Dan Standard Penetration Test (SPT) Pada Tanah Berpasir. 
Berdasarkan Gambar 5a. hasil perbandingan daya dukung fondasi berdasarkan data CPT S-1 dan CPT S-2 menunjukan kemiripan trend hingga kedalaman \pm 10.00 meter, dengan rerata daya dukung seperti dalam Tabel 1.

Tabel 1. Rerata Daya Dukung Fondasi dengan Pengujian CPT.

\begin{tabular}{ccccc}
\hline \multirow{2}{*}{ Pengujian } & \multicolumn{4}{c}{ Rerata Daya Dukung Fondasi (Ton) } \\
\cline { 2 - 5 } & $\mathrm{D}=15 \mathrm{~cm}$ & $\mathrm{D}=20 \mathrm{~cm}$ & $\mathrm{D}=25 \mathrm{~cm}$ & $\mathrm{D}=30 \mathrm{~cm}$ \\
\hline CPT S-1 & 2.21 & 3.81 & 6.09 & 8.48 \\
CPT S-2 & 3.68 & 6.43 & 10.08 & 14.28 \\
Rerata & 2.94 & 5.12 & 8.08 & 11.38 \\
Perbedaan (\%) & $40 \%$ & $41 \%$ & $40 \%$ & $41 \%$ \\
\hline
\end{tabular}

Sumber: Analisa Daya Dukung Fondasi.

Nilai daya dukung dalam Tabel 1. menunjukkan bahwa pengujian CPT memberikan nilai pengujian yang memiliki perbedaan hingga mencapai $40 \%$, hal ini dapat menggambakan bahwa pengujian CPT sangat sensitif akan adanya gangguan di dalam tanah, sehingga nilai pembacaannya bisa sangat bervariasi. Kemudian berdasarkan Gambar 5b. hasil perbandingan daya dukung fondasi berdasarkan data SPT BH-1 dan SPT BH-2 menunjukan kemiripan trend hingga kedalaman \pm 10.00 meter, dengan rerata daya dukung seperti dalam Tabel 2.

Tabel 2. Rerata Daya Dukung Fondasi dengan Pengujian SPT.

\begin{tabular}{ccccc}
\hline \multirow{2}{*}{ Pengujian } & \multicolumn{4}{c}{ Rerata Daya Dukung Fondasi (Ton) } \\
\cline { 2 - 5 } & $\mathrm{D}=15 \mathrm{~cm}$ & $\mathrm{D}=20 \mathrm{~cm}$ & $\mathrm{D}=25 \mathrm{~cm}$ & $\mathrm{D}=30 \mathrm{~cm}$ \\
\hline SPT BH-1 & 2.69 & 4.52 & 6.83 & 9.61 \\
SPT BH-2 & 2.59 & 4.40 & 6.68 & 9.42 \\
Rerata & 2.64 & 4.46 & 6.75 & 9.52 \\
Perbedaan (\%) & $3.5 \%$ & $2.8 \%$ & $2.3 \%$ & $2.0 \%$ \\
\hline
\end{tabular}

Sumber: Analisa Daya Dukung Fondasi.

Hasil rerata daya dukung pengujian SPT memiliki perbedaan yang tidak terlalu signifikan yaitu berkisar antara 2,0\% hingga 3,5\%, hal ini menunjukkan bahwa tingkat konsistensi pengujian SPT relative tinggi, dengan menunjukkan nilai pengujian yang tidak berbeda jauh dengan kondisi tanah yang hampir serupa. Kemudian berdasarkan Gambar 6. hasil perbandingan daya dukung fondasi berdasarkan data CPT dan data SPT menunjukan kemiripan trend hingga kedalaman \pm 10.00 meter, dengan perbandingan nilai daya dukung fondasi seperti dalam Tabel 3. 
Tabel 3. Perbandingan Daya Dukung Berdasarkan Pengujian CPT dan SPT.

\begin{tabular}{ccccc}
\hline \multirow{2}{*}{ Pengujian } & \multicolumn{4}{c}{ Rerata Daya Dukung Fondasi (Ton) } \\
\cline { 2 - 5 } & $\mathrm{D}=15 \mathrm{~cm}$ & $\mathrm{D}=20 \mathrm{~cm}$ & $\mathrm{D}=25 \mathrm{~cm}$ & $\mathrm{D}=30 \mathrm{~cm}$ \\
\hline CPT & 2.94 & 5.12 & 8.08 & 11.38 \\
SPT & 2.64 & 4.46 & 6.75 & 9.52 \\
Perbedaan $(\%)$ & $10.4 \%$ & $12.8 \%$ & $16.4 \%$ & $16.3 \%$ \\
\hline
\end{tabular}

Sumber: Analisa Daya Dukung Fondasi.

Tabel 3. menunjukkan perbedaan daya dukung antara pengujian CPT dengan SPT sebesar 10,4\% sampai 16,3\%. Tingkat kemiripan trend kurva pada Gambar 6. terjadi hingga kedalaman \pm 10.00 meter, lebih dari itu nilai daya dukung fondasi tidak menunjukkan trend yang sama, hal ini dapat disebabkan kepadatan lapisan dibawah sudah mulai berbeda-beda untuk masing-masing titik pengujian.

\section{Kesimpulan dan Saran}

\subsection{Kesimpulan.}

Berdasarkan penelitian yang telah dilakukan maka dapat ditarik kesimpulan sebagai berikut:

1. Jenis tanah di daerah penelitian di dominasi oleh tanah berpasir.

2. Rerata nilai daya dukung pengujian CPT dari kedalaman 0.00 meter sampai 10.00 meter berkisar antara 2,94 ton sampai 11,38 ton dengan diameter fondasi $15 \mathrm{~cm}$ hingga $30 \mathrm{~cm}$.

3. Rerata nilai daya dukung pengujian SPT dari kedalaman 0.00 meter sampai 10.00 meter berkisar antara 2,64 ton sampai 9,52 ton dengan diameter fondasi $15 \mathrm{~cm}$ hingga $30 \mathrm{~cm}$.

4. Perbedaan daya dukung pengujian CPT dan SPT berkisar antara 10,4\% sampai $16,3 \%$

5. Berdasarkan analisis yang dilakukan dapat diketahui bahwa pengujian SPT satu dengan yg lainnya dengan kondisi lapisan tanah yang hampir serupa memiliki perbedaan nilai pengujian yang lebih kecil sebesar 2,0\% sampai 3,5\% jika dibandingkan dengan CPT yang mencapai 40\%, sehingga pengujian SPT menghasilkan nilai yang lebih konsisten.

\subsection{Saran.}

Berdasarkan penelitian yang telah dilakukan maka dapat ditarik saran bahwa sebaiknya dilakukan test CPT dan SPT di laboratorium sehingga homogenitas tanah dan kepadatannya dapat dikontrol dan perlu dipergunakannya data yang lebih banyak untuk mendukung analisis yang lebih mendetail.

Perbandingan Daya Dukung Tiang Pancang Berdasarkan Pengujian Cone Penetration Test (CPT) Dan Standard Penetration Test (SPT) Pada Tanah Berpasir. 


\section{Daftar Pustaka}

[1] I. W. Ariyana and I. N. Sinarta, "Kapasitas Dukung Fondasi Diatas Tanah Timbunan Sampah Sebagai Usaha Mitigasi Bencana," in Senats3 (Seminar Nasional Teknik Sipil), 2019, p. GT-25-35.

[2] A. I. Candra, A. Yusuf, and A. R. F, "Studi Analisis Daya Dukung Pondasi Tiang Pada Pembangunan Gedung Lp3M Universitas Kadiri,” J. CIVILA, vol. 3, no. 2, p. 166, 2018.

[3] J. Zhou, E. Li, M. Wang, X. Chen, X. Shi, and L. Jiang, "Feasibility of Stochastic Gradient Boosting Approach for Evaluating Seismic Liquefaction Potential Based on SPT and CPT Case Histories," J. Perform. Constr. Facil., vol. 33, no. 3, 2019.

[4] P. Jarast and M. Ghayoomi, "Numerical Modeling of Cone Penetration Test in Unsaturated Sand inside a Calibration Chamber,” Int. J. Geomech., vol. 18, no. 2, 2018.

[5] P.-Q. Mo, A. M. Marshall, and Y. Hai-Sui, "Interpretation of Cone Penetration Test Data in Layered Soils Using Cavity Expansion Analysis," J. Geotech. Geoenviron. Eng, vol. 143, no. 1, 2017.

[6] A. I. Candra, "ANALISIS DAYA DUKUNG PONDASI STRAUSS PILE PADA PEMBANGUNAN GEDUNG MINI HOSPITAL UNIVERSITAS KADIRI," Ukarst, vol. 1, no. 1, pp. 63-70, 2017.

[7] S. K. Vanapalli and F. M. O. Mohamed, "Bearing Capacity and Settlement of Footings in Unsaturated Sands," Int. J. GEOMATE, vol. 5, no. 1, pp. 596-604, 2013.

[8] S. Alta, J. Prakoso, Z. Zakaria, and I. Sophiaan, "DAYA DUKUNG PONDASI DALAM DAERAH PANYIPATAN, TANAH LAUT, KALIMANTAN SELATAN BERDASARKAN HASIL STANDARD PENETRATION TEST," Padjadjaran Geosci. Journal., vol. 3, no. 1, pp. 1-8, 2019.

[9] A. I. Candra, S. Anam, Z. B. Mahardana, and A. D. Cahyono, "STUDI KASUS STABILITAS STRUKTUR TANAH LEMPUNG PADA JALAN TOTOK KEROT KEDIRI MENGGUNAKAN LIMBAH KERTAS,”vol. 2, no. 2, pp. 88-97, 2018.

[10] I. N. Sinarta and I. W. Ariyana Basoka, "The potential of liquefaction disasters based on the geological, CPT, and borehole data at southern Bali Island," J. Appl. Eng. Sci., vol. 17 , no. 4, pp. 535-540, 2019.

Perbandingan Daya Dukung Tiang Pancang Berdasarkan Pengujian Cone Penetration Test (CPT) Dan Standard Penetration 
[11] M. Al-Khazaali and S. K. Vanapalli, "Experimental Investigation of Single Model Pile and Pile Group Behavior in Saturated and Unsaturated Sand," J. Geotech. Geoenviron. Eng., vol. 145, no. 12, 2019.

[12] F. Han, R. Salgado, M. Prezzi, and L. Jeehee, "Axial Resistance of Nondisplacement Pile Groups in Sand," J. Geotech. Geoenviron. Eng., vol. 145, no. 7, 2019.

[13] M. Al-Khazaali and S. K. Vanapalli, "Experimental model to investigate the axial forcedisplacement behavior of a pipeline in unsaturated sandy soil," in In Proc., 70th Canadian Geotechnical Conf., 2017.

[14] P. W. Mayne, "Generalized CPT method for evaluating yield stress in soils," in GeoCongress 2014 Technical Papers at Geocharacterization and Modeling for Sustainability, 2014.

[15] A. S. Bradshaw, A. C. Morales-Velez, and C. D. P. Baxter, "Evaluation of existing CPT correlations in silt," Geotech. Eng. J. SEAGS AGSSEA, vol. 43, no. 4, p. 10, 2012.

[16] P. Q. Mo, A. M. Marshall, and H. S. Yu, "Centrifuge modelling of CPT in layered soils," in Geotechnical and Geophysical Site Characterization 4-Proc., 4th Int. Conf. on Site Characterization 4, 2013.

[17] P. Q. Mo, A. M. Marshall, and H. S. Yu, "Centrifuge modelling of cone penetration tests in layered soils," Géotechnique, vol. 65, no. 6, pp. 468-481, 2015.

[18] J. Walker and H. S. Yu, "Analysis of the cone penetration test in layered clay," Géotechnique, vol. 60, no. 12, pp. 939-948, 2010.

[19] H. C. Hardiyatmo, Analisis dan Perancangan Fondasi II, 2nd ed. Yogyakarta: Gadjah Mada University Press, 2010.

[20] H. C. Hardiyatmo, Analisis dan Perencanaan Fondasi I, 2nd ed. Yogyakarta: Gadjah Mada University Press, 2011.

[21] S. N. R. Listanti, D. Darsono, and Y. M. Purwana, "A Comparison between Drilling and Standard Penetration Test (SPT) Data to the Electrical Resistivity Sounding with Schlumberger Configuration in UNS Area," Indones. J. Appl. Phys., vol. 8, no. 2, pp. 67-74, 2018.

Perbandingan Daya Dukung Tiang Pancang Berdasarkan Pengujian Cone Penetration Test (CPT) Dan Standard Penetration 
[22] E. T. R. Dean and R. Mohammed, "Simplified Shockwave Analysis of the Standard Penetration Test," Int. J. Geomech., vol. 14, no. 6, 2014.

[23] J. N. Honeycutt, S. E. Kiser, and J. B. Anderson, "Database Evaluation of Energy Transfer for Central Mine Equipment Automatic Hammer Standard Penetration Tests," J. Geotech. Geoenviron. Eng., vol. 140, no. 1, 2014. 